\title{
57. On the Direction of Gene Conversion
}

\author{
By Hidenori Hayashida*) and Takashi Miyata*),**) \\ (Communicated by Motoo KimurA, M. J. A., May 13, 1985)
}

Gene conversion is thought to be an important mechanism for generating diversity of members of multigene family.1)-6) There are many examples demonstrating the occurrence of gene conversion in several eukaryotic multigene families during their evolution, ${ }^{6}$ ) but little is known about the direction of gene conversion. Knowledges about it may be of particular importance for further understanding of the precise mechanism of diversity and evolution of multigene family.7) Class I genes of the major histocompatibility complex may be an interesting example for this: These genes are known to be highly polymorphic ${ }^{8)}$ and this diversity was proposed to be generated by unidirectional gene conversion from $Q_{a}$, Tla regions to $\mathrm{K}, \mathrm{D}$ and $\mathrm{L}$ regions in the mouse. ${ }^{9)}$ In this communication, we demonstrate an example of gene conversion for which the direction of genetic information transfer could unequivocally be determined.

Human and mouse genomes contain multiple copies of distinct yet closely related IFN- $\alpha$ genes (ref. 10) for review). It was shown that human IFN- $\alpha$ $\mathrm{H}$ resembles the members of one group in the $\mathrm{N}$-terminal portion, while its C-terminal portion is similar to the members of another group and was suggested that the unique pattern of amino acid sequence similarity in IFN- $\alpha \mathrm{H}$ was derived by gene conversion. ${ }^{10)}$ Comparison at the nucleotide level provides further information in this regard.

By gene conversion, the nucleotide sequence of part or all of a gene in a multigene family is replaced by the corresponding sequence of another, thereby becoming identical in sequence. As a result, the degree of sequence homology between the genes involved changes abruptly around the break point where the DNA sequences recombine. ${ }^{1,5)}$ When the nucleotide sequence of IFN- $\alpha 2 \mathrm{H}$ (or H) gene, a member of human IFN- $\alpha$ multigene family, was compared with those of closely related genes, $\mathrm{C} 1$ (or $\mathrm{C}$ ), $\mathrm{J}$ and L, of the family, a remarkable discontinuity in $K_{s}$ value (nucleotide difference per site at silent positions ${ }^{11)}$ ) along the length of the coding sequences was observed for all the three pairs $2 \mathrm{H} / \mathrm{C} 1,2 \mathrm{H} / \mathrm{J}$ and $2 \mathrm{H} / \mathrm{L}$ (Fig. 1). In addition, the three pairs exhibit a similar profile to each other. In contrast, pairwise comparisons of the $2 \mathrm{H}$ gene with other genes including two murine genes show no apparent discontinuity in $K_{s}$ value, but the profiles appear to be uniform over the entire coding regions, somewhat fluctuating around the mean. These results strongly suggest that the IFN- $\alpha 2 \mathrm{H}$ gene exchanged its $3^{\prime}$ portion of the coding sequence with a common ancestral gene of $\mathrm{C} 1, \mathrm{~J}$ and $\mathrm{L}$ genes during evolution by gene conversion. Although the precise boundary at which gene conversion took place is obscure, we tentatively assigned codon 80 as a boundary on the basis of the distribution of $K_{s}$ value (see Fig. 1). For each of the $5^{\prime}$ terminal (codons 1-80) and $3^{\prime}$

*) Department of Biology, Faculty of Science, Kyushu University, Fukuoka 812, Japan.

**) National Institute of Genetics, Mishima 411, Japan. 
terminal (81-189) portions of the coding region, the corrected difference $K_{s}^{c}$ $\left(=-(3 / 4) \ln \left(1-(4 / 3) K_{s}\right)\right.$, ref. 16$\left.)\right)$ of silent position was calculated. It is apparent that the two portions differ significantly from each other in $K_{s}^{c}$ value for all the three pairs $2 \mathrm{H} / \mathrm{C} 1,2 \mathrm{H} / \mathrm{J}$ and $2 \mathrm{H} / \mathrm{L}$, but no distinguishable difference is seen, when human and murine IFN- $\alpha$ 's were compared. Thus the strong

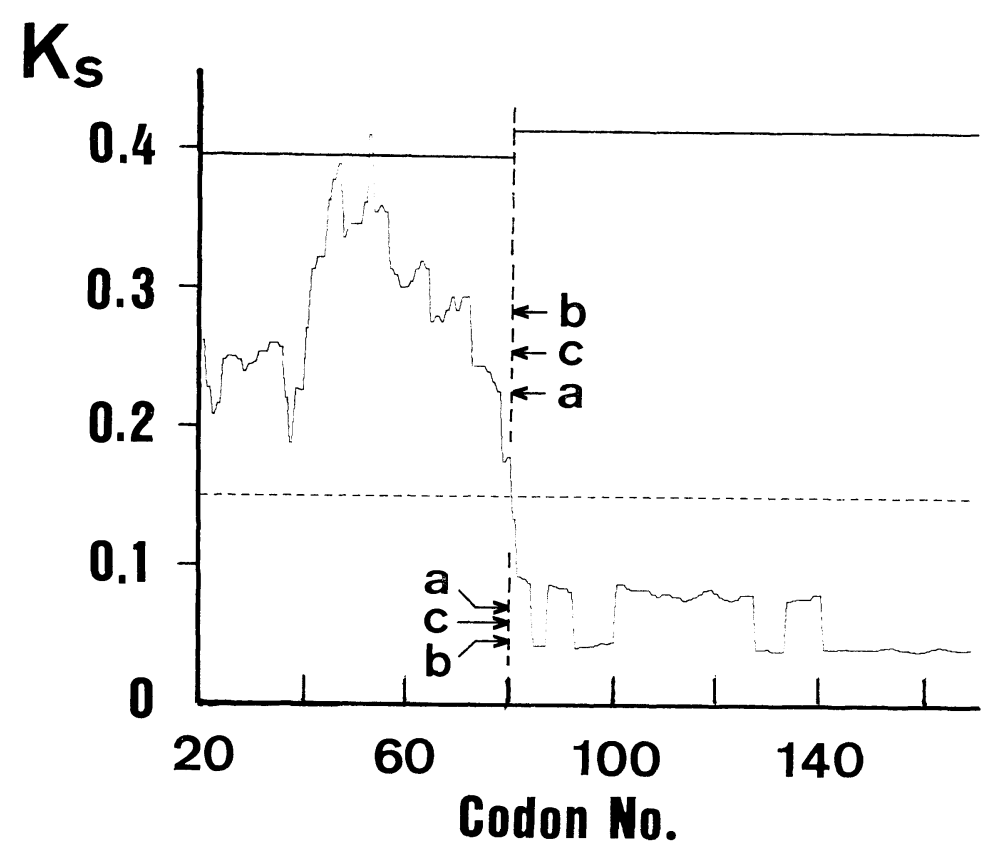

Fig. 1. Profile of nucleotide difference $\left(K_{s}\right)$ at silent positions of protein-encoding region as compared between human IFN- $\alpha 2 \mathrm{H}$ and $\mathrm{C} 1$ genes. For each segment of 40 codons long from codon position i to $\mathrm{i}+39(\mathrm{i}=1,149)$, the $K_{s}$ was calculated as described previously ${ }^{11)}$ and its value was plotted against codon position $\mathrm{i}+20$. Vertical dotted line represents the boundary (codon position 80) at which the $K_{s}$ value changes sharply and coincides with the average value over the entire coding region (horizontal dotted line). Horizontal arrows indicate the average $K_{s}$ values of the $5^{\prime}($ codons 1-80) and 3'(81-189) regions for gene pairs a) $2 \mathrm{H} / \mathrm{C} 1$, b) $2 \mathrm{H} / \mathrm{J}$ and c) $2 \mathrm{H} / \mathrm{L}$. Horizontal lines represent the average $K_{s}$ values of 16 gene pairs between human $\operatorname{IFN}_{-} \alpha(\mathrm{A}, \mathrm{B}, \mathrm{C} 1, \mathrm{D}, \mathrm{F}, 2 \mathrm{H}, \mathrm{J}$ and $\mathrm{L})$ and mouse IFN- $\alpha$ ( $\alpha 1$ and $\alpha 2)$. Sequence data were taken from refs. 12)-14) for human IFN- $\alpha$ 's and ref. 15) for mouse IFN- $\alpha$ 's.

homology in the $3^{\prime}$ portion is likely to be the result of gene conversion (note that no gene conversion is possible to occur between genes of different species).

The $K_{s}^{c}$ values of $5^{\prime}$ and $3^{\prime}$ portions provide information about the timing of the latest gene conversion by which the DNA sequence of the $3^{\prime}$ portion was exchanged between the $2 \mathrm{H}$ gene and the ancestor of $\mathrm{C} 1, \mathrm{~J}$ and $\mathrm{L}$ genes ${ }^{5)}$ : The $K_{s}^{c}$ values of the $3^{\prime}$ portion are given as 0.006 and 0.60 for pairs $2 \mathrm{H} /(\mathrm{C} 1, \mathrm{~J}, \mathrm{~L})$ and human IFN- $\alpha$ /murine IFN- $\alpha$, respectively. Thus the gene conversion is expected to have occurred around $8(=75 \times 0.006 / 0.60)$ million years ago, if constant rate of silent changes is postulated.

A phylogenetic consideration also reveals the direction of genetic infor- 
mation transfer by gene conversion: Fig. 2, a-b show phylogenetic trees among the human IFN- $\alpha \mathrm{J}, \mathrm{F}, \mathrm{H}(2 \mathrm{H})$ and $\mathrm{D}$ genes constructed on the basis of $K_{s}^{c}$ values for the $5^{\prime}$ and $3^{\prime}$ portions of the coding region, respectively. The two phylogenetic trees are essentially identical in topology and position of each nodal point, except for a lineage leading to $H$. The tree " $b$ " can be derived

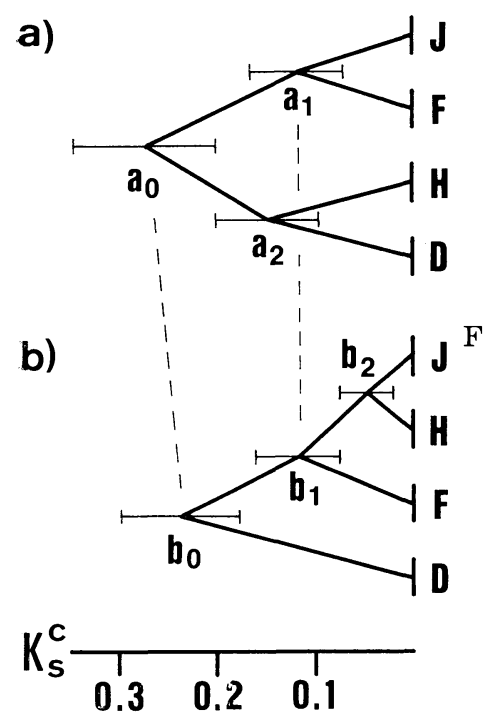

Fig. 2. Evolutionary relationships among human IFN$\alpha \mathrm{J}, \mathrm{F}, \mathrm{D}$ and $\mathrm{H}(2 \mathrm{H})$ genes. Phylogenetic trees of a), $5^{\prime}$ portion (codons $1-80$ ) and b), $3^{\prime}$ portion (codons 81-189). Both trees were constructed on the basis of the corrected differences $K_{s}^{c}$ at the silent positions of protein-encoding region. Standard deviations were estimated as $\sqrt{K_{s}^{c} / N_{s}}$, where $N_{s}$ is the number of silent sites. ${ }^{\left.1{ }^{\top}\right)} a_{0}-a_{2}$ and $b_{0}-b_{2}$ indicate ancestral nodes.

frcm the tree " $\mathrm{a}$ " by simply moving the branch $\mathrm{a}_{2}-\mathrm{H}$ and locating the point $a_{2}$ on the line $a_{1}-J$ without altering the relationships of other lineages. This implies that the DNA sequence of the $3^{\prime}$ portion of the $\mathrm{H}$ gene was converted by the corresponding sequence of the $\mathrm{J}$ gene (an ancestral gene of $\mathrm{C}, \mathrm{J}$ and $\mathrm{L}$ in the strict sense). In conclusion, a part of DNA sequence encoding the IFN- $\alpha$ $\mathrm{H}$ gene was rectified by the sequence of a common ancestral gene of $\mathrm{C}, \mathrm{J}$ and $\mathrm{L}$ about 8 million years ago by gene conversion. Judging from the location of the break point in homology, the boundary of gene conversion is likely to be around codon 80 .

As shown above, the followings are required for determining the direction of gene conversion from sequence comparisons among members of a multigene family: (1) Sequences of at least four different members are available for comparison. (2) Their tree topologies differ between regions of both sides of the boundary at which sequences recombined. The number of genes compared can be reduced to three rather than four, if evolutionary rates of both regions are known or they evolve with similar rates as in the cases of intron regions and silent positions of protein-encoding regions. $\left.\left.{ }^{5}, 18\right), 19\right)$

Acknowledgements. We thank Miss K. Mitsuyasu for technical assistance. This work was supported in part by grants from the Ministry of Education, Science and Culture of Japan. 


\section{References}

1) Miyata, T. et al. (1980): Proc. Natl. Acad. Sci. USA, 77, 2143-2147.

2) Slightom, J. L., Blechl, A. E., and Smithies, O. (1980) : Cell, 21, 627-638.

3) Baltimore, D. (1981): ibid., 24, 592-594.

4) Ohta, T. (1982): Proc. Natl. Acad. Sci. USA, 79, 3251-3254.

5) Hayashida, H., and Miyata, T. (1983): ibid., 80, 2671-2675.

6) Hayashida, H. et al. (1985) : Proc. Japan Acad., 61B, 149-152 (1985).

7) Dover, G. A. (1982): Nature, 299, 111-117.

8) Klein, J. (1979): Science, 203, 516-521.

9) Steinmetz, M., and Hood, L. (1983): ibid., 222, 727-733.

10) Weissmann, C. et al. (1982) : Primary and Tertiary Structure of Nucleic Acids and Cancer Research (eds. M. Miwa et al.). Japan Sci. Soc. Press, Tokyo, pp. 1-22.

11) Miyata, T., and Yasunaga, T. (1980): J. Mol. Evol., 16, 23-36.

12) Goeddel, D. V. et al. (1981): Nature, 290, 20-26.

13) Lawn, R. M. et al. (1981): Science, 212, 1159-1162.

14) Ullrich, A. et al. (1982): J. Mol. Biol., 156, 467-486.

15) Shaw, G. D. et al. (1983): Nucleic Acids Res., 11, 555-573.

16) Kimura, M. (1983): The Neutral Theory of Molecular Evolution. Cambridge University Press, Cambridge.

17) Miyata, T., and Hayashida, H. (1982): Nature, 295, 165-168.

18) Miyata, T., Yasunaga, T., and Nishida, T. (1980) : Proc. Natl. Acad. Sci. USA, 77, 7328-7332.

19) Miyata, T. et al. (1982): J. Mol. Evol., 19, 28-35. 